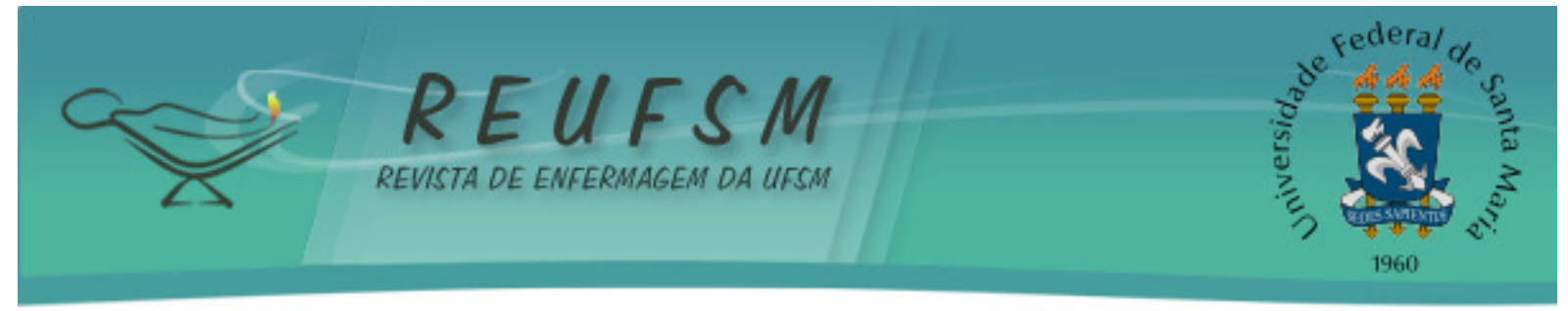

ARTIGO ORIGINAL

\title{
PREPARO E PERCEPÇÕES DE GESTANTES SOBRE AS VIAS DE PARTO
}

\section{PREGNANT WOMEN'S PREPARATION AND PERCEPTIONS ABOUT MODE OF DELIVERY \\ PREPARACIÓN Y PERCEPCIONES DE MUJERES EMBARAZADAS ACERCA DE LA VÍA DEL PARTO}

\author{
Cleidiane Lopes dos Santos ${ }^{1}$ \\ Cleunir de Fátima Candido De Bortoli ${ }^{2}$ \\ Lisie Alende Prates ${ }^{3}$ \\ Kelly Bernardi Guimarães ${ }^{4}$ \\ Gisele lopp Massafera ${ }^{5}$ \\ Priscila Bisognin ${ }^{6}$
}

Doi: $10.5902 / 2179769219283$

RESUMO: Objetivo: conhecer o preparo e as percepções de gestantes sobre as vias de parto. Método: pesquisa descritiva, qualitativa, desenvolvida com oito gestantes, em setembro de 2014, em um município no sudoeste do Estado do Paraná. Os dados foram coletados por meio de entrevista semiestruturada e analisados pela técnica de análise de conteúdo temática da proposta operativa. Resultados: o parto vaginal emergiu como a via preferencial das participantes. A preparação para o parto se deu, especialmente, durante o pré-natal, sendo o médico o profissional mais envolvido nas orientações, mas também aquele que mais influenciou na decisão sobre a via de parto. Conclusão: embora as participantes tenham revelado uma preferência pelo parto vaginal, frente às imposições e à falta de conhecimentos, no preparo pré-natal, elas foram convencidas a realizar a cesárea.

Descritores: Parto normal; Cesárea; Educação em saúde; Enfermagem.

ABSTRACT: Aim: to know the preparation and perceptions of pregnant women about mode of delivery. Method: descriptive, qualitative research, developed with eight pregnant women, in September 2014, in a municipality in the southwest region of the State of Paraná. The data were collected through semi-structured interview and analyzed by thematic content analysis technique of operative proposal. Results: the vaginal birth has emerged as the participants' preferred manner of delivery. The preparation for childbirth took place, especially, during the prenatal period, being the doctor the professional who was mostly involved in the guidelines, but also the one that most influenced the decision concerning the mode of delivery. Conclusion: although the participants have revealed a preference for vaginal birth, because of impositions and lack of knowledge, at prenatal preparation they were convinced to perform the caesarean.

Descriptors: Natural childbirth; Cesarean section; Health education; Nursing.

\footnotetext{
${ }^{1}$ Enfermeira egressa da Faculdade de Pato Branco (FADEP). Pato Branco, Paraná, Brasil. E-mail: cleidy_bss@hotmail.com

${ }^{2}$ Enfermeira. Mestre em Enfermagem. Docente da FADEP. Pato Branco, Paraná, Brasil. E-mail: cleunir_candido@hotmail.com

${ }^{3}$ Enfermeira. Doutoranda do Programa de Pós-Graduação em Enfermagem da Universidade Federal de Santa Maria. Enfermeira Assistencial no Hospital Universitário de Santa Maria. Santa Maria, Rio Grande do Sul, Brasil. E-mail: lisiealende@hotmail.com

${ }^{4}$ Enfermeira. Docente da FADEP. Pato Branco, Paraná, Brasil. E-mail: kellyguimaraes@fadep.br

${ }^{5}$ Enfermeira. Docente da FADEP. Pato Branco, Paraná, Brasil. E-mail: giseleiopp@fadep.br

${ }^{6}$ Arte-educadora. Enfermeira. Mestre em Enfermagem. Caxias do Sul, Rio Grande do Sul Brasil. E-mail: pribisognin@gmail.com
} 


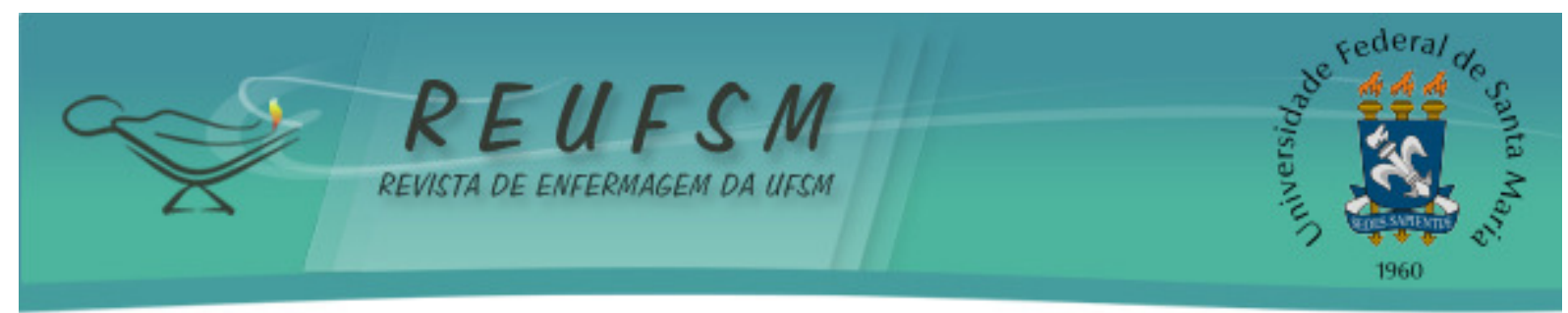

RESUMEN: Objetivo: conocer la preparación y percepciones de las mujeres embarazadas acerca de la vía del parto. Método: investigación descriptiva, cualitativa, desarrollada con ocho mujeres embarazadas, en septiembre de 2014, en un municipio del estado de Paraná. Los datos fueron recogidos a través de entrevista semiestructurada y analizados por la técnica del contenido temático de la propuesta operativa. Resultados: el parto vaginal se ha convertido en la vía de parto preferida de las participantes. La preparación para el parto ocurrió, especialmente, durante el período prenatal, siendo el médico lo profesional más implicado en las directrices, pero también el que más influyó en la decisión sobre la vía de parto. Conclusión: aunque las participantes revelan una preferencia por el parto vaginal, frente a los imposiociónes y la falta de conocimientos, en preparación prenatal, ellas fueron convencidas a realizar la cesárea.

Descriptores: Parto Normal; Cesárea; Educación em Salud; Enfermería.

\section{INTRODUÇÃO}

No Brasil, discute-se amplamente a frequência das cesarianas, uma vez que estas têm apresentado um aumento contínuo desde a década de 1990, sendo que, em 2011, esta via de parto superou a proporção de partos vaginais com 53,88\%. Esses valores extrapolam as recomendações da Organização Mundial da Saúde, que sugere que as cesáreas não ultrapassem $15 \%$ do total dos partos. ${ }^{1-2}$

Nos últimos anos, o processo de nascimento sofreu modificações, passando de um evento feminino natural, para um acontecimento técnico e medicalizado. Essa transformação acabou mitificando o parto vaginal, tornando-o um evento desconhecido e amedrontador para algumas mulheres. ${ }^{3}$ Entre elas, a percepção negativa sobre o processo parturitivo é relacionada, principalmente, à dor e à forma como ele é conduzido, motivando-as a optar pela cesariana. ${ }^{1}$ Diante da necessidade de tornar o parto uma experiência tranquila e positiva, tem-se a atenção pré-natal como um espaço de preparação para a gestante.

O período gestacional pode representar um momento especial na vida da mulher, no qual ela vivencia alterações e readaptações anatômicas, fisiológicas, bioquímicas, sociais e culturais, além de um processo de preparação para as mudanças e novas responsabilidades. Envolve um contexto repleto de incertezas, em que se manifestam sentimentos, dentre os quais se destacam o medo e a insegurança. ${ }^{4}$

Nesse sentido, o pré-natal tem como finalidade proporcionar cuidados à mulher e ao feto, visando contribuir para uma gestação e nascimento saudáveis. Para isso, o acompanhamento gestacional compreende a valorização dos aspectos psicossociais e o desenvolvimento de atividades educativas. ${ }^{2} \mathrm{~A}$ educação em saúde não pode representar um repasse de informações, pois cada mulher possui seus próprios medos, crenças e expectativas e está inserida em um contexto sociocultural. ${ }^{5}$ É fundamental que o profissional de saúde promova a autonomia da mulher, protegendo o seu direito na escolha da via de parto e resgatando sua autonomia para desenvolver o protagonismo no processo de nascimento. ${ }^{6}$

Assim, o presente estudo foi impulsionado pelas seguintes questões orientadoras: "Como ocorre a preparação da gestante para o parto?" e "Qual a percepção da gestante sobre as vias de parto?". A partir destas questões foi traçado o objetivo, que foi conhecer o preparo e as percepções de gestantes sobre as vias de parto. 


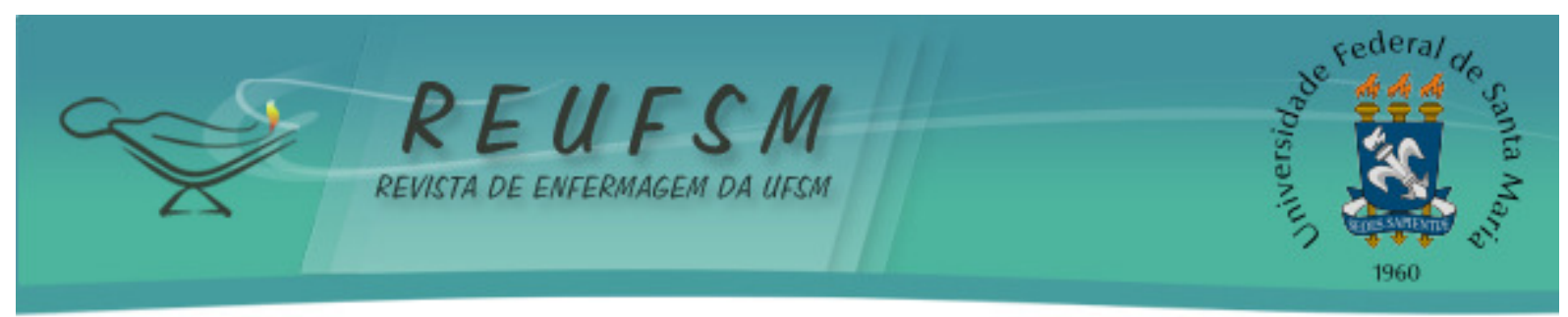

MÉTODO

Estudo descritivo e com abordagem qualitativa. ${ }^{7}$ o cenário do estudo foi a Estratégia Saúde da Família (ESF) de um município no sudoeste do Estado do Paraná, Brasil, com aproximadamente 3.365 habitantes, ${ }^{8}$ os quais são assistidos pela ESF e uma equipe do Programa de Agente Comunitário de Saúde (PACS).

Durante o período de coleta de dados, a ESF desenvolvia encontros mensais, com abordagem educativa, tendo como público-alvo as gestantes assistidas no serviço. Neles, eram discutidas temáticas associadas ao período gestacional. 0 grupo de educação em saúde era composto por 20 gestantes. Entretanto, no estudo, participaram oito gestantes, que atenderam ao critério de seleção por apresentarem idade superior a 18 anos. As demais, devido à faixa etária, foram excluídas do estudo.

A coleta dos dados ocorreu em setembro de 2014 e se utilizou a entrevista individual semiestruturada como técnica de coleta de dados. Inicialmente, buscou-se identificar algumas questões de caracterização das gestantes, como idade, estado civil, escolaridade e religião, além de dados relativos à gestação atual, a saber, a data da última menstruação e data provável do parto.

Primeiramente, realizou-se o preenchimento destas informações e, a seguir, desenvolveu-se a entrevista guiada pelas seguintes questões orientadoras: você recebeu informação sobre os tipos de parto no pré-natal? Quem te orientou? Em sua opinião, qual é a melhor via de parto? Por quê? Quais as vantagens desta via para seu bebê? Qual é a sua expectativa em relação ao momento do parto? Você sabe em qual situação é indicada a cesárea? Você já ouviu algum relato, opinião ou crença sobre parto normal ou cesárea? O que foi relatado e por quem? Esse relato mudou a sua opinião? Qual a sua maior fonte de informação a respeito de gestação e parto? Internet/televisão, médico, família, amigos? Como está sendo seu acompanhamento pré-natal? Suas dúvidas estão sendo esclarecidas, recebe informações em relação à gestação e ao parto? Você já sabe qual o tipo de parto será realizado? Quem participou desta decisão? Médico? Família? Ou foi uma decisão sua? Já passou por uma gestação anterior? Se sim, como foi a experiência? Qual foi o tipo de parto? Essa experiência anterior está lhe influenciando de alguma forma na atual?

As entrevistas foram previamente agendadas e ocorreram no domicílio das gestantes, sendo que os relatos foram gravados e, posteriormente, transcritos. 0 tempo de duração das entrevistas oscilou entre 30 e 45 minutos. A construção dos dados foi conduzida pelas questões orientadoras, buscando conhecer as percepções das gestantes acerca da via de parto.

Os dados foram analisados pela técnica de análise de conteúdo temática da proposta operativa. ${ }^{7}$ Logo, na primeira etapa, que compreendeu a fase exploratória, buscou-se compreender o grupo estudado e o contexto socioeconômico em que as gestantes estavam inseridas. Em um segundo momento, denominado de fase interpretativa, desenvolveu-se a ordenação dos dados, a partir da transcrição, leitura e releitura das entrevistas. Assim, realizou-se a leitura horizontal e exaustiva do material coletado, seguida da leitura transversal, que permitiu agrupar o material em categorias, as quais foram analisadas e discutidas com a literatura.

Este estudo respeitou os preceitos éticos da resolução número 466/2012, do Conselho Nacional de Saúde. Para preservar o anonimato das participantes, utilizou-se o sistema alfanumérico, por meio da letra " $G$ " (de gestante) seguida de um numeral. ${ }^{9} 0$ projeto de pesquisa teve aprovação do Comitê de Ética em Pesquisa, em agosto de 2014, com protocolo de pesquisa número 105/14. 


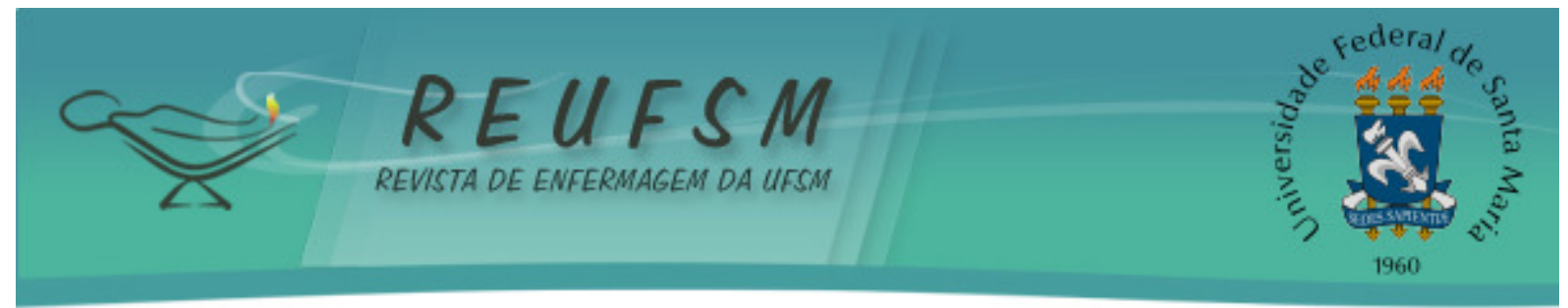

\section{RESULTADOS}

As participantes encontravam-se na faixa etária dos 24 aos 36 anos. A maioria estava em união consensual, possuía ensino médio completo, declarou-se católica e estava vivenciado o terceiro trimestre gestacional. $\mathrm{Na}$ análise das falas das entrevistadas, emergiram três categorias denominadas "Construindo concepções sobre as vias de parto"; "Preparando-se para o processo de parturição"; e "Escolhendo a via de parto".

\section{Construindo concepções sobre as vias de parto}

As gestantes apresentavam diferentes concepções sobre as vias de parto. Estas foram construídas e influenciadas pelas vivências e percepções de outros indivíduos, como os familiares, amigas e pessoas do contexto comunitário.

Antigamente era só parteira, né? Fazia parto normal. Elas [mulheres da família] contam que não sabem como que as crianças nasciam, porque hoje é tudo no hospital, é tudo estéril, mais rápido. Antigamente era uma parteira, em casa, que fazia. Colocava uma bacia de água, cortava, às vezes, com tesoura, não era estéril. As crianças sobreviviam e não tinham infecção nenhuma. (G1)

O que falam é que a cesárea é ruim. O que mais falam é que a mãe não pode levantar. A mãe [puérpera] não pode fazer as coisas, tem que se cuidar bastante. Já o parto normal, muitas que tiveram falaram que é bom, que a mãe já sai caminhando. A alta também é menos [o tempo de permanência no hospital]. Eu gostaria de ter parto normal, porque todo mundo fala que é melhor. (G4)

As mulheres apresentavam concepções próprias sobre as vias de parto. Contudo, algumas percepções estavam relacionadas às vivências de outras mulheres. Elas se mostravam decididas em relação ao parto vaginal e realizaram ponderações em relação às concepções manifestadas por outros indivíduos.

Desde que eu descobri que eu estava grávida, sempre tive o pensamento que queria parto normal e não mudou nada. Tem mulheres que dizem "ah, eu quero cesárea, porque eu não consigo". É uma insegurança que elas têm. Às vezes, elas não têm o conhecimento do pós-operatório. Porque eu sempre penso no pósoperatório e o risco. Parto normal, você chega lá, é tudo natural, contrai, dilata, nasce. Cesárea é uma coisa mais artificial, porque você vai para o centro cirúrgico, usa anestesia, vai ser feito corte. Se não for bem estéril, você pode pegar uma infecção. O nenê corre risco. Até porque tem que estourar a bolsa. Então, eu sempre preferi o parto normal e vou conseguir, eu acho, e não vou mudar. (G1)

Muitas mulheres têm medo de parto normal e preferem para não ter dor. No fim, acabam tendo dor e fazendo cesárea. Mas eu acho 


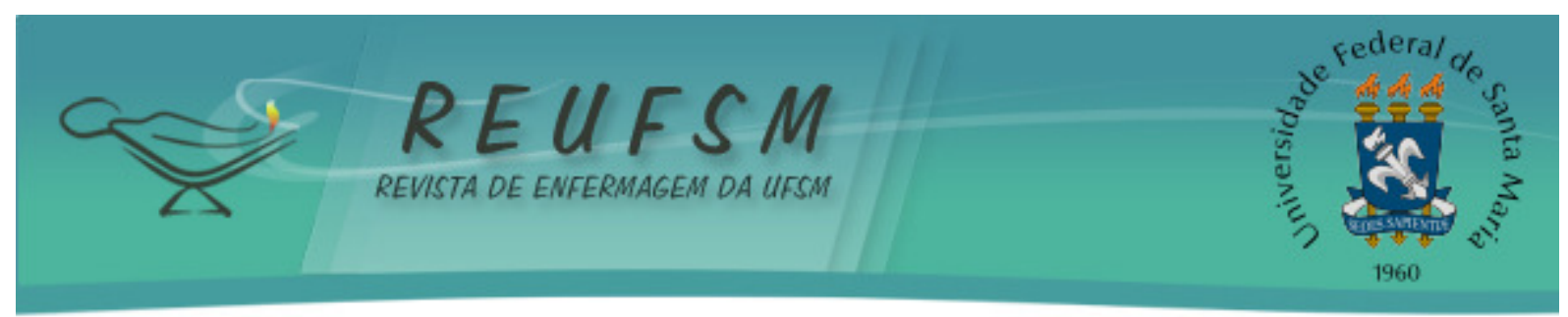

que elas estão erradas [sobre o parto normal]. Elas têm medo na verdade. Não pode ter medo. (G2)

Minha cunhada optou pela cesariana. O parto normal ela não quis. Tem mulheres que não querem, e já umas que querem. Mas eu não mudei minha opinião depois do que ela disse. (G8)

Os relatos expressam o posicionamento das participantes, além da preferência pela via vaginal. Ainda, infere-se que as percepções e as experiências de vida de outras pessoas da rede de apoio social não alteraram as concepções das gestantes.

Além das informações transmitidas, especialmente pelas mulheres mais próximas, também existiam as concepções construídas pelas próprias mulheres em relação ao processo parturitivo e as vias de parto. Essas concepções foram construídas a partir de suas experiências prévias ou de suas expectativas.

Parto normal para a criança é muito bom, não corre o risco de aspirar, porque na cesárea acontecem casos que eles [profissionais de saúde] estouram a bolsa e o risco do bebê de aspirar. Então, é bem complicado, né? Eu acho que mais é isso e pela minha recuperação também, que a mãe levanta já pode tomar banho, e a cesárea não, precisa de um cuidado maior, por ter ponto, por ser um risco também a mais, né? [...] É tudo mais complicado. Por isso, eu acho que o normal é o mais recomendável. (G1)

O parto normal eu acho melhor. Eu gostaria de ter parto normal. Só que eu não pude, por causa da dilatação, contração eu não tive. (G4)

O parto normal é melhor para mãe, né? Apesar que, eu acho que a cesárea é melhor para o nenê, mas eu acho que o parto normal é melhor. (G6)

As concepções das entrevistadas em relação ao parto vaginal se mostraram arraigadas em seus conhecimentos sobre as vantagens desta via, bem como na percepção de que o parto vaginal envolve um evento natural e fisiológico. Com relação à cesárea, as mulheres descreveram situações que elas consideravam que justificavam a sua realização.

Quando a mãe não tem dilatação, pode ter contração, mas não tem dilatação. Quando o nenê está sentado, quando o nenê é muito grande ou, às vezes, é uma cesárea de emergência, quando a criança é prematura, ai é indicada a cesárea, ou gemelar também. Gemelar hoje é só cesárea. (G1)

Situação de risco, quando a criança não se encaixa, quando a mãe também tem problema, né? (G2)

Por exemplo, eu tive o [primeiro filho] de cesárea, porque ele não dilatava, né? Agora parece que a médica falou também que talvez seja cesárea, por isso. (G6) 


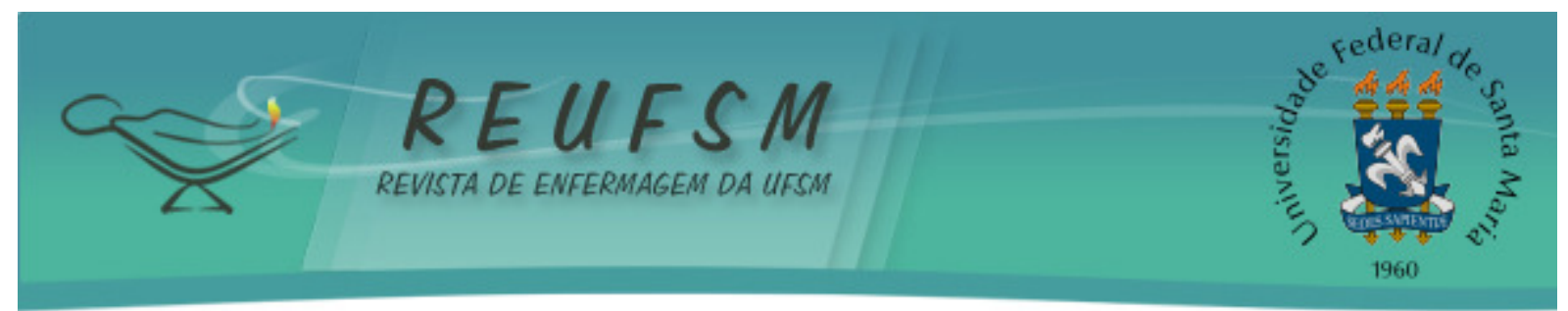

As indicações pontuadas pelas participantes para a realização de uma cesárea envolviam orientações fornecidas, principalmente, pelos profissionais de saúde. Nestas situações, elas acreditavam que a melhor via de parto era a cesárea.

\section{Preparando-se para o processo de parturição}

Todas as participantes afirmaram ter recebido orientações sobre o processo de parturição e sobre as vias de parto no pré-natal. Dentre os profissionais de saúde que as orientaram, três gestantes referiram terem sido orientadas somente pelo médico, duas somente pelo enfermeiro, uma apenas pelo agente comunitário de saúde (ACS), uma pelo enfermeiro e pelo médico, e uma pelo médico e o ACS.

Apesar de algumas mulheres terem destacado o médico como o profissional de saúde que mais compartilhou saberes, verificou-se que uma das participantes vivenciou uma situação negativa com este profissional. Diante disso, ela adotou uma postura passiva e passou a buscar informações com as ACS e familiares.

A médica não está me informando. Um dia eu perguntei a ela, ela falou grosso comigo [foi ríspida]. Então, é bom ficar quieta. Eu gosto mais de pedir [informações] para minha cunhada, que já tem experiência, e pelas agentes de saúde, que elas sabem lidar, falar com as pessoas. (G8)

Frente à situação relatada, pondera-se que o profissional de saúde apresentou uma atitude impositiva frente às dúvidas manifestadas pela gestante. Ela deixou de buscar este profissional para auxiliá-la na compreensão e preparação para o processo de parturição.

As participantes também foram questionadas sobre as situações em que eram trabalhadas as orientações envolvendo o período gravídico-puerperal. Essas atividades educativas se desenvolviam tanto nas consultas, por meio de ações individuais, como nos grupos educativos, em atividades coletivas.

As reuniões que tem no grupo de gestantes são bem interessantes. A gente tira bastante dúvida, porque trabalha a nutricionista, a fisioterapeuta, a enfermagem, as próprias agentes. É bem legal. (G1)

Nas visitas semanais das agentes de saúde, elas repassam informações satisfatórias. (G3)

É possível verificar que, durante as atividades educativas, fossem elas individuais ou coletivas, as gestantes verbalizavam suas dúvidas. Possivelmente, os profissionais de saúde mencionados além de orientar as gestantes, também permitiam que elas atuassem ativamente nesses processos educativos.

Ao participar de forma ativa, as mulheres podem manifestar seus saberes, embora empíricos, ao mesmo tempo em que os profissionais de saúde compartilham seus conhecimentos científicos. Nesse contexto, constrói-se um somatório de aprendizados, que podem contribuir para que a mulher e sua família vivenciem plenamente o período gravídico-puerperal. 


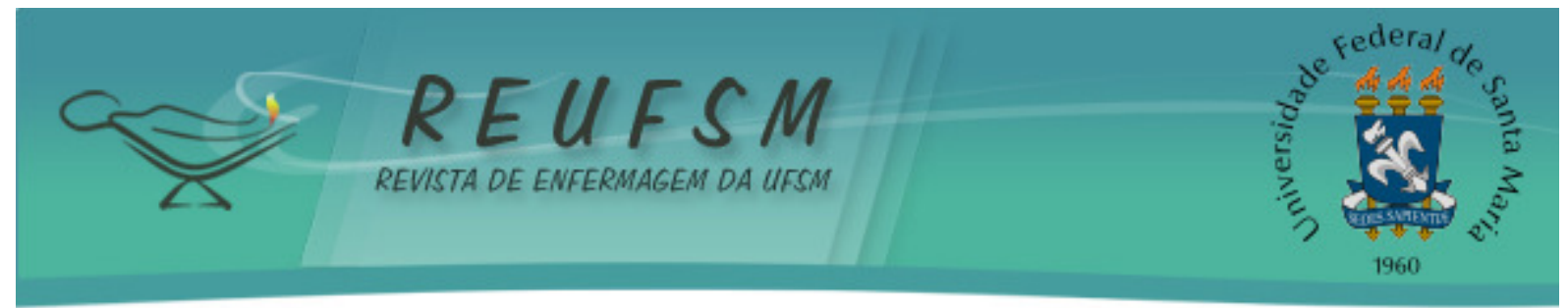

\section{Escolhendo a via de parto}

Ao manifestar a via de parto desejada, prevaleceu, nas falas das entrevistadas, a escolha pelo parto vaginal, denominado por elas como parto normal. Foram relatadas diversas vantagens na escolha por essa via, sendo a recuperação no pós-parto umas das vantagens mais relatadas.

Pela recuperação, eu quero parto normal, porque eu conheço o pósoperatório da cesárea e o pós-operatório normal, e por conhecer os dois, eu prefiro o normal. (G1)

A recuperação é mais fácil, né? A cesariana já e mais complicada. Tem que se cuidar mais. (G8)

Entre as motivações relatadas pelas mulheres, identificou-se também a preocupação com o bem-estar do recém-nascido. As participantes apontaram como vantagens a descida do leite materno e o contato precoce com a criança.

O parto normal é melhor para respiração e a imunidade do bebê também. (G3)

A mãe já pode estar com a criança, pode acompanhar a criança, pode pegar mais ela. E a cesárea tem que ficar mais deitada. (G4)

A gente sofre só na hora, né? Depois, você fica melhor e você pode cuidar do nenê sozinha, não precisa de ninguém para ajudar. Bem melhor, porque o leite materno já desce na hora, e a cesárea demora mais, e o contato com o nenê é bem maior. (G7)

Elas ainda reconheceram o parto vaginal como um evento natural para o organismo feminino. Por isso, consideravam que esta via apresentava vantagens em relação à cesárea.

Por ser um parto normal, que é o natural, você não usa anestesia. Então, para criança isso é muito bom, ele se encaixa bem. (G1)

Os antecedentes obstétricos podem influenciar na escolha do parto atual, porém, não devem ser o principal fator nessa escolha. É essencial que o profissional de saúde tenha conhecimento sobre o histórico obstétrico da gestante, a fim de identificar possíveis inseguranças oriundas de experiências anteriores com o processo de parturição.

No meu caso é para fazer a operação [laqueadura] depois, né? Daí vai ter que ser [cesárea]. (G3)

O médico já confirmou que vai ser cesárea, porque eu não tive contração nem dilatação das outras, já foi duas cesáreas, né? Essa é a terceira. (G4) 


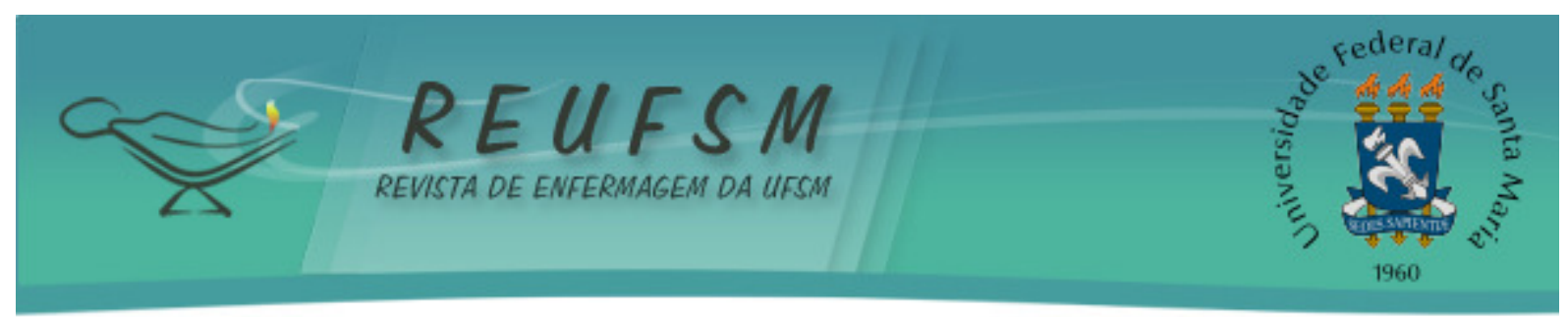

Para mim, ela [médica] ainda não falou [qual será a via de parto], porque eu tenho bronquite, daí falta respiração, aí ela não sabe bem certo. (G5)

Ela [médica] disse que, provavelmente, vai ser cesárea, porque eu sou pequeninha e como eu não dilato. Então, pode ser que seja cesárea, né? Antes foi cesárea e se eu pudesse ter tido parto normal, eu queria, e agora também, tanto que eu falei que se eu puder ter parto normal, eu quero ter, mas como a médica que decide, vamos ver até no final o que vai dar. (G6)

Ela [médica] ainda não me informou se vai ser cesariana ou parto normal. (G8)

Apesar das indicações apresentadas pelo médico, depreende-se que as mulheres desejavam o parto vaginal. Contudo, frente às orientações fornecidas pelos profissionais, associada à falta de conhecimentos pertinentes e adequados, elas foram convencidas a realizar a cesárea.

\section{DISCUSSÃO}

Durante o período gestacional, as percepções construídas sobre o parto podem interferir nas decisões, como também no próprio comportamento da mulher no momento de parturição. Nesse sentido, os profissionais de saúde precisam respeitar as percepções e escolhas da mulher, procurando apoiá-la, orientá-la e esclarecê-la em relação aos medos e dúvidas que se manifestam neste período. ${ }^{10}$

As concepções das mulheres acerca da via de parto podem ser influenciadas por pessoas que convivem com elas, durante o período gestacional. Contudo, nem sempre as vivências desses indivíduos são esclarecedoras, necessitando da atuação do profissional de saúde, a fim de orientar a gestante e outros indivíduos da rede de apoio social em relação às dúvidas que possam emergir. ${ }^{3}$

No presente estudo, as participantes revelaram uma preferência pelo parto vaginal. Esta percepção se mostrou associada às influências exercidas por mulheres que participavam do contexto de vida das gestantes. Em estudo, ${ }^{10}$ também se verificou que as mulheres mais próximas das entrevistadas, especialmente familiares e amigas, apresentavam papel fundamental na elaboração das concepções sobre o processo de parturição e na escolha pela via de parto.

As participantes que revelaram preferência pela cesárea mencionaram os antecedentes obstétricos como fatores determinantes desta escolha. Pesquisas ${ }^{11-12}$ revelam que, em alguns casos, o momento do nascimento é programado por meio da cesárea, a fim de proporcionar maior segurança ao médico que pode intervir diante de um evento que é imprevisível, reduzindo, assim, o tempo despendido com este atendimento e gerenciando melhor sua agenda e remuneração, entre outros aspectos.

Ademais, há de se considerar que ao recomendar a cesárea, o profissional pode reduzir o tempo despendido com a paciente, o que lhe permite gerenciar sua agenda, além de gerar melhor remuneração. Logo, pondera-se que algumas das indicações para realização da cesárea, muitas vezes, são fictícias. Contudo, são transmitidas pelos profissionais de saúde por uma questão de conveniência destes. ${ }^{11}$ 


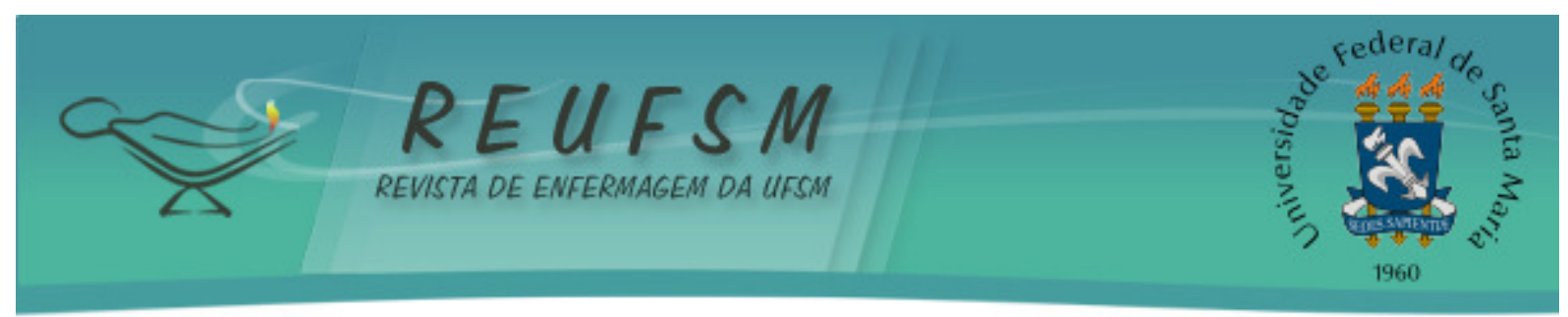

O processo de preparação da mulher para a parturição ocorre desde a gestação, por meio de informações e orientações compartilhadas com os profissionais de saúde. ${ }^{13}$ Essa preparação pode auxiliá-la a vivenciar este processo com maior segurança e tranquilidade, pois, habitualmente, a falta de informações gera, na mulher, preocupações desnecessárias, bem como expectativas frustradas. Logo, a realização de atividades de educação em saúde pode contribuir para uma vivência positiva desta fase. ${ }^{14}$

As participantes do estudo, em sua totalidade, relataram ter recebido orientações durante o pré-natal. Neste processo, participaram o agente comunitário de saúde, o enfermeiro e, principalmente, o médico. Outro estudo também revelou que o médico envolvia-se com as ações de educação em saúde no pré-natal, embora outros profissionais também atuassem, contudo, de forma mais restrita. ${ }^{14}$

Da mesma forma, outro estudo também observou que o enfermeiro não atua constantemente nas ações educativas no pré-natal. ${ }^{15}$ Estes achados são relevantes, pois em vários contextos, observa-se que este é o profissional de saúde que se envolve diretamente nas atividades educativas, enquanto outros profissionais se abstém deste processo. ${ }^{16-17}$

Quando o profissional de saúde oferta um momento ou espaço, na consulta prénatal ou nos próprios grupos educativos, para que a mulher possa revelar seus conhecimentos e questionamentos, constrói-se um ambiente educativo pautado na reflexão e na transformação das práticas de cuidado em saúde. Em contraponto, quando se entendem as ações de educação em saúde como um mero processo de depósito de ensinamentos, em que impera o repasse e a transmissão de conhecimentos à usuária e sua família, para que estes os memorizem e reproduzam, esse processo não produz sentidos, nem ao profissional de saúde quanto menos à gestante e seus familiares. ${ }^{18-19}$

As ações em grupos educativos direcionadas às gestantes se tornaram um instrumento essencial, pois quando os conhecimentos são trabalhados adequadamente nesses espaços, permite-se que as participantes sejam empoderadas e desenvolvam autonomia e autoconfiança frente às suas escolhas. Ao compartilhar experiências e conhecimentos sobre gestação, parto e puerpério, as mulheres podem reduzir o medo e a ansiedade, permitindo-se vivenciar ativamente cada um destes eventos. ${ }^{20}$

A escolha pelo parto vaginal se evidencia nos relatos das participantes como uma opção desejada, especialmente, devido à recuperação pós-parto e o bem-estar da criança. Estas vantagens também foram apontadas em estudo, ${ }^{21}$ no qual se constatou o desejo das participantes por esta via de parto.

Ademais, as razões presentes nas escolhas da mulher em relação ao parto vaginal, independentemente de qual fossem, expressaram uma expectativa de vivenciar o processo de parturição sem dor, em um menor período de tempo possível e com menor permanência no ambiente hospitalar, visando, ainda, uma melhor recuperação e o bem-estar do filho. As vantagens apontadas pelas entrevistadas também se assemelharam aos achados de um estudo de revisão, que buscou identificar, em pesquisas nacionais e internacionais, a percepção do parto vaginal e da cesárea por mulheres que os vivenciaram. Nesse sentido, a anestesia apareceu como algo temido pelas mulheres, tanto àquelas que já apresentavam experiências anteriores como àquelas que não apresentavam. Também foi identificada a concepção do parto vaginal como um processo natural e saudável para o binômio mãe-bebê. ${ }^{22}$

A escolha da via de parto pelo profissional de saúde e não pela mulher, em consequência de antecedentes obstétricos, é frequente. Além disso, o procedimento de laqueadura emergiu, neste estudo, como uma justificativa para a realização da cesárea, como também foi apontado em outra pesquisa. ${ }^{10}$ Portanto, apesar das indicações apresentadas pelo médico, pondera-se que a maioria das mulheres deseja o parto vaginal. 


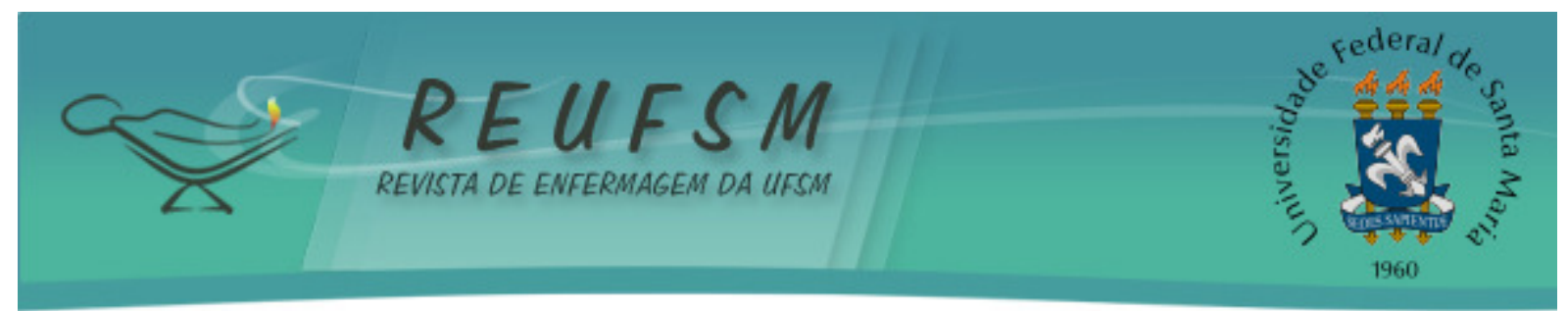

Contudo, elas são persuadidas, tanto pelos profissionais de saúde quanto pela sociedade, e acabam optando pela cesárea.

As experiências não bem sucedidas em partos anteriores, o medo da dor, a influência cultural e familiar e o desejo em realizar a laqueadura tubária se apresentam como fatores determinantes na escolha desta via de parto. Com isso, muitas mulheres, mesmo desejando o parto normal no início da gravidez, acabam optando pela cesárea no decorrer da gestação. Entre os fatores que contribuem para essa decisão da mulher, destacam-se também a atuação do profissional no acompanhamento pré-natal, a qualidade das orientações fornecidas e, até mesmo, a ausência ou inconsistência destas. ${ }^{3}$

\section{CONCLUSÃO}

A vivência do período gravídico-puerperal pode ser singular e marcante na vida da mulher, podendo ser positiva ou negativa, dependendo, dentre tantos fatores, das concepções existentes sobre o processo de parturição e das orientações compartilhadas pelos familiares e profissionais de saúde nesse período. Dessa forma, a análise dos resultados desta pesquisa apontou para a necessidade da realização de ações educativas nos serviços de saúde durante o pré-natal, que possam contribuir para o aprendizado e maior empoderamento e autonomia da mulher frente ao processo de parturição e decisão sobre a melhor via de parto para si e seu filho.

As participantes consideraram o parto vaginal a melhor via de nascimento para o bebê e apresentaram justificativas para esta escolha, as quais estavam pautadas em saberes ora empíricos, ora científicos. Dentre os motivos alegados para a realização do parto vaginal, elas listaram vantagens relacionadas à saúde da mulher, como o menor tempo de recuperação no pós-parto e a possibilidade de sentir menos dor, assim como vantagens atreladas à saúde da criança, como o contato precoce com o bebê, a vantagem de desempenhar os seus primeiros cuidados e a descida do leite materno.

Entretanto, a autonomia e a decisão da mulher sobre a escolha da via de parto nem sempre são respeitadas, embora sejam fundamentais para a humanização do cuidado fornecido à parturiente. A decisão do obstetra sobre a via de parto se mostrou como uma conduta comum e, muitas vezes, inquestionada pelas mulheres. Dentre as justificativas relatadas pelas entrevistadas para a indicação da cesárea, estavam os antecedentes obstétricos relativos às cesáreas prévias e à associação ao procedimento de laqueadura.

Entende-se que uma das limitações deste estudo abrange a realização da coleta de dados com um grupo de mulheres de uma mesma região, que apresentava culturas semelhantes. 0 número reduzido de participantes também pode representar um fator limitador, apesar de ter compreendido toda a população de mulheres que atendiam aos critérios de seleção. Nesse sentido, sugere-se a realização de estudos em diferentes cenários sobre o objeto de estudo, a fim de conhecer o preparo e as percepções de outras gestantes sobre as vias de parto. Ademais, a utilização de outras técnicas de coleta de dados também pode desvelar e, até mesmo, ampliar outras perspectivas sobre a temática, considerando, por exemplo, a percepção dos próprios profissionais de saúde sobre as vias de parto, bem como as indicações apontadas por estes para a escolha de cada uma destas vias e os contextos profissionais e institucionais em que estas foram construídas.

\section{REFERÊNCIAS}

1. Domingues RMSM, Dias MAB, Pereira MN, Torres JA, D'Orsi E, Pereira APE, et al. Processo de decisão pelo tipo de parto no Brasil: da preferência inicial das mulheres à via de parto 


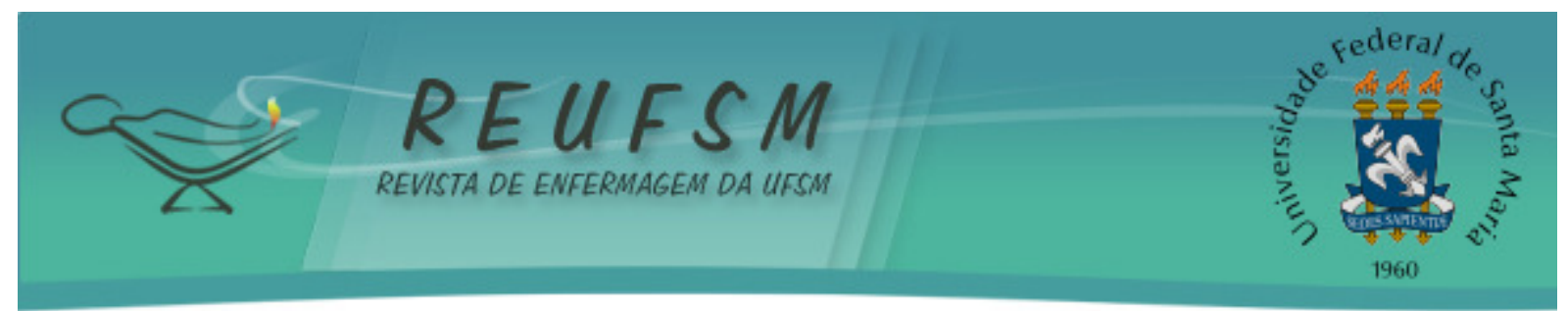

final. Cad Saúde Pública [Internet]. 2014 [acesso em 2015 mar 7];30 Supl 1:101-16. Disponível em: http://www.scielo.br/pdf/csp/v30s1/0102-311X-csp-30-s1-0101.pdf.

2. Brasil. Ministério da Saúde. Atenção ao pré-natal de baixo risco. Brasília: Editora do Ministério da Saúde; 2012.

3. Weidle WG, Medeiros CRG, Grave MTQ, Dal Bosco SM. Escolha da via de parto pela mulher: autonomia ou indução? Cad Saúde Colet [Internet]. 2014 [acesso em 2015 mar 7];22(1):46-53. Disponível em: http://www.scielo.br/pdf/cadsc/v22n1/1414-462X-cadsc22-01-00046.pdf.

4. Benute GRG, Nomura RY, Santos AM, Zarvos MA, Lucia MCS, Francisco RPV. Preferência pela via de parto: uma comparação entre gestantes nulíparas e primíparas. Rev Bras Ginecol Obstet [Internet]. 2013 [acesso em 2015 mar 09];35(6):281-5. Disponível em: http://www.scielo.br/pdf/rbgo/v35n6/v35n6a08.pdf.

5. Líbera BD, Saunders C, Santos MMAS, Rimes KA, Brito FRSS, Baião MR. Avaliação da assistência pré-natal na perspectiva de puérperas e profissionais de saúde. Ciênc Saúde Coletiva [Internet]. 2011 [acesso em 2015 mar 08];16(12):4855-64. Disponível em: http: //www.scielo.br/pdf/csc/v16n12/34.pdf.

6. Pimenta LF, Ressel LB, Santos CC, Wilhelm LA. Percepção de mulheres sobre a escolha da via de parto: estudo descritivo. Online Braz J Nurs [Internet]. 2013 [acesso em 2015 mar 07];12(1):135-44. Disponível em: http://www.objnursing.uff.br/index.php/nursing/article/viewFile/3963/2021.

7. Minayo MCS. O desafio do conhecimento: pesquisa qualitativa em saúde. $14^{\mathrm{a}}$ ed. São Paulo: Hucitec; 2014.

8. Instituto Brasileiro de Geografia e Estatística (IBGE). Cidades [Internet]. Rio de Janeiro; 2016 [acesso em 2016 abr 09]. Disponível em: http: / / cidades.ibge.gov.br/xtras/perfil.php?codmun=410322.

9. Brasil. Ministério da Saúde. Resolução $n^{\circ}$ 466, de 12 de dezembro de 2012. Aprova as diretrizes e normas regulamentadoras de pesquisa envolvendo seres humanos. Brasília: Ministério da Saúde; 2012.

10. Figueiredo NSV, Barbosa MCA, Silva TAS, Passarini TM, Lana BN, Barreto J. Fatores culturais determinantes da escolha da via de parto por gestantes. HU Revista [Internet]. 2010 [acesso em 2015 mar 10];36(4):296-306. Disponível em: http://hurevista.ufjf.emnuvens.com.br/hurevista/article/viewFile/1146/460.

11. Patah LEM, Malik AM. Modelos de assistência ao parto e taxa de cesárea em diferentes países. Rev Saúde Pública [Internet]. 2011 [acesso em 2015 mar 21];45(1):185-94. Disponível em: http://www.revistas.usp.br/rsp/article/viewFile/32944/35531.

12. Oliveira AR. Fatores associados e indicações para a prática de cesariana: um estudo caso-controle. Rev Port Med Geral Fam [Internet]. 2013 [acesso em 2015 mar 21];29(3):151-9. Disponível em: http://www.scielo.mec.pt/pdf/rpmgf/v29n3/v29n3a03.pdf.

13. Costa AP, Bustorff LACV, Cunha ARR, Soares MCS, Araújo VS. Contribuições do pré-natal para o parto vaginal: percepção de puérperas. Rev RENE. 2011;12(3):548-54.

14. Francisquini AR, Higarashi IH, Serafim D, Bercini LO. Orientações recebidas durante a gestação, parto e pós-parto por um grupo de puérperas. Cienc Cuid Saúde [Internet]. 2010 [acesso em 2015 mar 21];9(4):743-51. Disponível em: http://periodicos.uem.br/ojs/index.php/CiencCuidSaude/article/view/13826/7193. 


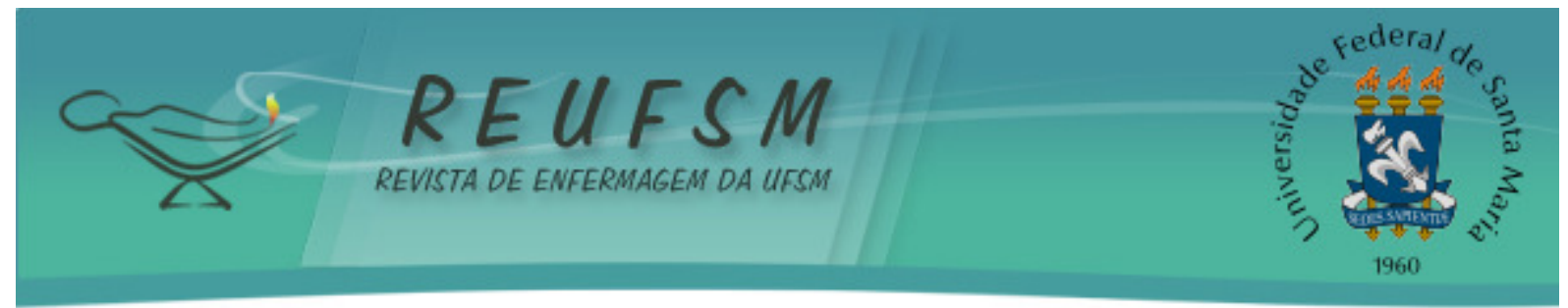

15. Souza VB, Roecker S, Marcon SS. Ações educativas durante a assistência pré-natal: percepção de gestantes atendidas na rede básica de Maringá-PR. Rev Eletrônica Enferm [Internet]. 2011 [acesso em 2015 abr 20];13(2):199-210. Disponível em: http://www.fen.ufg.br/fen_revista/v13/n2/v13n2a06.htm.

16. Lima SS. Enfermagem no pré-natal de baixo risco na estratégia saúde da família. Aquichan [Internet]. 2013 [acesso em 2015 mar 21];13(2):261-9. Disponível em: http: //www.scielo.org.co/pdf/aqui/v13n2/v13n2a12.pdf.

17. Barreto CN, Ressel LB, Santos CC, Wilhelm LA, Silva SC, Alves CN. Atenção prénatal na voz das gestantes. Rev Enferm UFPE on line [Internet]. 2013 [acesso em 2015 mar 21];7(5):4354-63. Disponível em: http://www.revista.ufpe.br/revistaenfermagem/index.php/revista/article/view/435 5/pdf_2721.

18. Pinafo E, Nunes EFPA, González AD, Garanhani ML. Relações entre concepções e práticas de educação em saúde na visão de uma equipe de saúde da família. Trab Educ Saúde [Internet]. 2011 [acesso em 2015 mar 21];9(2):201-21. Disponível em: http://www.scielo.br/pdf/tes/v9n2/03.pdf.

19. Figueiredo MFS, Rodrigues-Neto JF, Leite MTS. Modelos aplicados às atividades de educação em saúde. Rev Bras Enferm [Internet]. 2010 [acesso em 2015 mar 21];63(1):11721. Disponível em: http://www.scielo.br/pdf/reben/v63n1/v63n1a19.pdf.

20. Zampieri MFM, Gregório VRP, Custódio ZAO, Regis MI, Brasil C. Processo educativo com gestantes e casais grávidos: possibilidade para transformação e reflexão da realidade. Texto \& Contexto Enferm [Internet]. 2010 [acesso em 2015 mar 10];19(4):719-27. Disponível em: http://www.scielo.br/pdf/tce/v19n4/15.pdf.

21. Costa e Silva SP, Prates RCG, Campelo BQA. Parto normal ou cesariana? Fatores que influenciam na escolha da gestante. Rev Enferm UFSM [Internet]. 2014 [acesso em 2015 fev 17];4(1):1-9. Disponível em: http://cascavel.ufsm.br/revistas/ojs2.2.2/index.php/reufsm/article/view/8861/pdf.

22. Velho MB, Santos EKA, Brüggemann OM, Camargo BV. Vivência do parto normal ou cesáreo: revisão integrativa sobre a percepção de mulheres. Texto \& Contexto Enferm [Internet]. 2012 [acesso em 2015 mar 21];21(2):458-66. Disponível em: http://www.scielo.br/pdf/tce/v21n2/a26v21n2.pdf.

Data de recebimento: $27 / 08 / 2015$

Data de aceite: 11/04/2016

Contato do autor responsável: Lisie Alende Prates

Endereço postal: Programa de Pós-Graduação em Enfermagem - Centro de Ciências da Saúde - Universidade Federal de Santa Maria - Avenida Roraima $n^{\circ} 1000$, Prédio 26 - Cidade Universitária - CEP: 97105-900, Santa Maria, RS, Brasil.

E-mail: lisiealende@hotmail.com 